\title{
First published record of urban malaria in Puerto Gaitán, Meta, Colombia
}

\author{
Luz Stella Buitrago', Helena Luisa Brochero²/+, Sascha N McKeon ${ }^{4}$, William Lainhart ${ }^{4}$, Jan E Conn ${ }^{3,4}$ \\ 'Unidad de Entomología, Secretaría Departamental de Salud del Meta, Villavicencio, Meta, Colombia Facultad de Agronomía, \\ sede Bogotá, Universidad Nacional de Colombia, Bogotá, Colombia ${ }^{3}$ Wadsworth Center, New York State Department of Health, \\ Slingerlands, NY, USA ${ }^{4}$ Department of Biomedical Sciences, School of Public Health, State University of New York at Albany, Albany, NY, USA
}

Patterns of malaria cases were compared between the department of Meta and the municipality of Puerto Gaitán, Colombia, to examine temporal change in malaria from 2005-2010. During this time frame in Meta the mean ratio was 2.53; in contrast, in Puerto Gaitán it was 1.41, meaning that a surprisingly high proportion of Plasmodium falciparum cases were reported from this municipality. A detailed analysis of data from Puerto Gaitán for 2009 and 2010 detected a significant difference $\left(\chi^{2}, p<0.001\right)$ in the distribution of plasmodia, with Plasmodium vivax more prevalent in 2009 and $\mathrm{P}$. falciparum in 2010. Males had the highest number of cases but there was no difference in the distribution of cases between sexes and years. In both years, for both sexes, people 16-40 accounted for the majority of cases $\left(58.9 \%\right.$ in 2009; $60.4 \%$ in 2010). There were significant differences in the distribution of both P. vivax ( $\chi^{2}$, $p<0.01)$ and $\mathrm{P}$. falciparum cases $\left(\chi^{2}, p<0.05\right)$ by geographic setting (urban vs. non-urban) between years. Urban cases of both P. vivax and P. falciparum are recorded in this study for the first time in Puerto Gaitán, possibly the result of area wide displacement and migration due to armed conflict.

Key words: Plasmodium falciparum - Plasmodium vivax - malaria cases - epidemiology - armed conflict - Colombia

In South America, Brazil and Colombia together report more than $70 \%$ of the annual malaria cases (Rodríguez et al. 2011), and concern about the incidence of malaria is increasing in Colombia due to an endemic/ epidemic pattern that maintains unstable endemic levels year after year (Caicedo et al. 2009, Arevalo-Herrera et al. 2012). Historically, malaria cases in Colombia have been dominated by Plasmodium vivax, accounting for approximately $70 \%$ of all reported cases (Chaparro et al. 2013); in contrast P. falciparum is mostly restricted to the Pacific region (Rodríguez et al. 2011). Drastic reduction of staff and central budgets for malaria control country-wide in the context of decentralization of services (Rodríguez et al. 2011) contributed to the weakening of vector-control activities which relied mainly on strategies such as residual house spraying, diagnosis and treatment (Brochero \& Quiñones 2008, Montoya-Lerma et al. 2011).

Colombia consists of six eco-epidemiological regions, including Orinoquia, within which the department of Meta is located (Fig. 1). Meta and Guaviare departments together reported $93 \%$ of all cases in Orinoquia

\footnotetext{
doi: $10.1590 / 0074-0276130217$

Financial support: National Institutes of Health (NIH), USA, grant

AI R01 54139-02 to JEC; Universidad Nacional de Colombia

Hermes QuiPu 201010012197 to EMB; NIH T32AI05532901,

"Training in Biodefense and Emerging Infectious Disease"

provided partial support for WL.

+Corresponding author: embrochero@unal.edu.co

Received 20 April 2013

Accepted 6 December 2013
}

(Padilla \& Peña 2002a,b) and both are included in the areas of the highest annual parasite index (API), i.e., 10671, for Colombia (Chaparro et al. 2013). Nevertheless, Meta ranked only eighth in case numbers by department for Colombia in 2010 (Chaparro et al. 2013).

The major regional vector in Orinoquia is Anopheles (Nyssorhynchus) darlingi Root (SEM 1957, Jiménez et al. 2012), which generally breeds along the margins of rivers (Faran 1980, Rejmánková et al. 1999, Vittor et al. 2009) and is abundant in Meta where there are several large rivers (Olano et al. 2001, Brochero et al. 2005). Additionally, An. darlingi has been found in fishponds in Colombia and Peru, suggesting adaptation to anthropogenic breeding sites (Olano et al. 2001, Vittor et al. 2006, 2009, reviewed in Hiwat \& Bretas 2011).

The municipality of Puerto Gaitán is located roughly $193 \mathrm{~km}$ (Fig. 1) from the departmental capital Villavicencio, and has approximately 17,161 inhabitants, including $6,178(36 \%)$ who live in or near the town centre and $10,983(64 \%)$ who live in nine nearby indigenous reserves, representing the Sikuani, Piapoco and Sáliba. The main local economic drivers are oil extraction, cattle ranching, small-scale agriculture, fishing, and tourism (Puerto Gaitán 2011). Oil extraction activities have resulted in unplanned urbanization, an influx of migrants seeking economic opportunities, and environmental degradation due to construction of new access roads and temporary (plastic) urban and peri-urban housing with very limited, if any, public services (Bolaños 2007). In rural areas, illegal agriculture and mining and social inequality, among other factors, interfere with access to public health services, resulting in considerable selfmedication. Also, because of armed conflict and the presence of insurgent troops along with legal military forces (Chaparro et al. 2013) in the nearby departments 
of Guaviare and Vichada (Fig. 1), many people have been compelled to migrate, sometimes carrying with them new or resistant Plasmodium strains from other Colombian endemic malaria regions (Arango et al. 2008).

Malaria transmission in Colombia is predominantly rural, although peripheral areas are highly affected (Méndez et al. 2000, Rodríguez et al. 2011). Urban malaria, which is now of global concern (Enayati \& Hemingway 2010) has been documented in Colombia (Olano et al. 1997, Ochoa \& Osorio 2006, Jiménez et al. 2012), but not previously in Puerto Gaitán or the department of Meta. There are local malaria cases in Puerto Gaitán, in both children and adults unlikely to have acquired the parasites in surrounding endemic areas (SDS Meta 2011).

The purpose of this study was (i) to examine changes in the Plasmodium vivax/Plasmodium falciparum ratio between the department of Meta and the municipality of Puerto Gaitán over six years (2005-2010); (ii) to evaluate associations between human demographic variables and Plasmodium infection in Puerto Gaitán in 2009 and 2010; and (iii) to seek evidence of local urban malaria transmission in this small town.

\section{MATERIALS AND METHODS}

Study site - The department of Meta is in the eastern Orinoco region of Colombia and consists of $29 \mathrm{mu}-$ nicipalities, including Puerto Gaitán, and 25 indigenous reserves, the latter representing $2 \%$ of the population (Gobernación del Meta 2004). The municipality of Puerto Gaitán extends from $3^{\circ} 05^{\prime}-4^{\circ} 08^{\prime} \mathrm{N}$ to $71^{\circ} 05^{\prime}-72^{\circ} 30^{\prime} \mathrm{W}$ and comprises an area of $17,492 \mathrm{~km}^{2}$, at an altitude of $149 \mathrm{~m}$, with an average annual temperature of $30^{\circ} \mathrm{C}$, and eight months of rainfall (April - November) followed by three dry months (December - March). The urban area is $11.6 \mathrm{~km}^{2}$, with $85 \%$ paved roads, and 4,145 houses, of which $80 \%$ have indoor plumbing. There are several nearby rivers (Manacacías, Planas, Tillavá, Yucao, Uva,

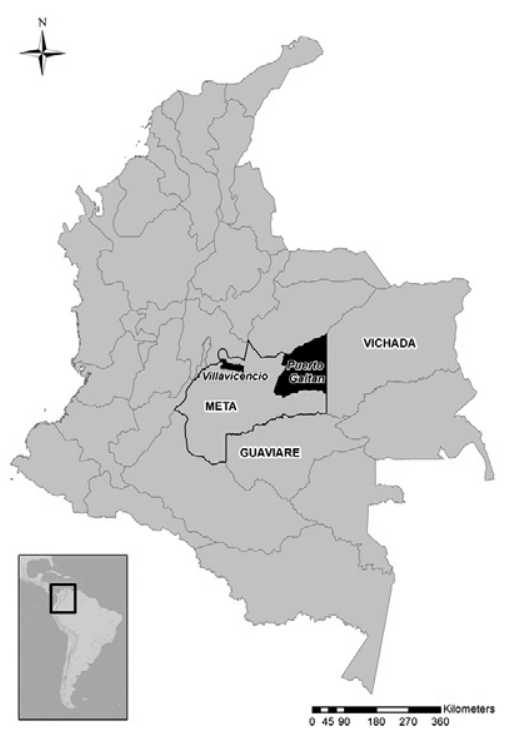

Fig. 1: map of Colombia showing the locations of the department of Meta and the municipality of Puerto Gaitán.
Iteviare, Tomo, and Muco) and natural lakes (Bolaños 2007). Four microscopists in the surrounding rural area and five medical personnel are responsible for the entire indigenous population. Rural malaria cases are treated by microscopists who provide medication based on diagnosis. Serious malaria cases are referred to the health care services in the town centre, and complicated cases are referred to one of the hospitals in Villavicencio, the capital of Meta. Both the registered microscopists and the contracted health care institutions in the municipality provide weekly reports of cases to the municipal Office of Prevention and Public Health, and from here to the department. Epidemiological and entomological surveillance, including vector control, is the responsibility of the department (SDS Meta 2011).

Epidemiological data - For epidemiological malaria case reporting in Colombia (including Meta), the number of positive slides from the Laboratorio de Salud Publica and Oficina de Vigilancia en Salud Pública from Secretaria Departamental de Salud del Meta, 2011 (SDS Meta 2011) was considered to be equivalent to the number of malaria cases (Padilla \& Montoya 2011). Epidemiological data from 2009 and 2010 for Puerto Gaitán were provided by the Alcaldia Municipal de Salud. Each house with a reported malaria case was geo-referenced with a hand-held GPS unit. Malaria cases data were deidentified by removing patient names prior to analysis.

Data analysis - An analysis of data from a six-year period was undertaken to evaluate patterns in malaria case numbers in the department of Meta compared with those in the municipality of Puerto Gaitán. For these data, cases of mixed infection with $P$. falciparum and $P$. vivax were added to totals of each of these parasites, as in Póvoa et al. (2003). In subsequent analyses, the data, from Puerto Gaitán in 2009 and 2010, were based on the total municipal population [urban and non-urban; SDS Meta (2011)]. Pearson's Chi-squared tests were used to determine whether the distribution of $P$. vivax or $P$. falciparum cases differed between 2009 and 2010 with respect to pertinent variables, including the patient's sex, age group (categorized as $0-10,11-15,16-40$ and $>40$ years; Camargo et al. 1994), and geographical setting (urban versus non-urban). Urban cases were defined as the positive slides from houses within the town limits of Puerto Gaitán, whereas non-urban were defined as those outside these limits. Due to the low number of mixed infections ( 6 cases in 2009 and 10 cases in 2010), and because Pearson's Chi-squared test assumes that all observations are independent, cases of mixed infection were excluded from these analyses.

\section{RESULTS AND DISCUSSION}

Six year malaria case trends in Meta and Puerto Gaitán - Malaria case data from the Department of Meta and from the municipality of Puerto Gaitán, Meta, Colombia were examined for 2005 through 2010. Between 2005 and 2010, the percentage of total malaria infections in Meta that occurred in Puerto Gaitán increased greatly, from $4 \%$ to $25 \%$. Previous reports suggest that the average ratio of $P$. vivax to $P$. falciparum cases ( $\mathrm{Pv} / \mathrm{Pf}$ ratio) is approximately 3:1 (Sivigila 2011a, b). As seen in Table 
$\mathrm{I}$, the $\mathrm{Pv} / \mathrm{Pf}$ ratio fluctuates around this reported average (Table I, mean 2.53, range 2.12-3.99). In every year, 2005-2010, $P$. vivax cases outnumbered $P$. falciparum cases in Meta. However, in the municipality of Puerto Gaitán, the Pv/Pf ratio varied widely (Table I; mean 1.41, range $0.57-3.02$ ). In 2005 , the ratio was 3.02 , and one year later it was 0.89 , meaning $P$. falciparum cases outnumbered $P$. vivax cases in Puerto Gaitán. The $\mathrm{Pv} / \mathrm{Pf}$ ratio again increased throughout 2007, 2008 and 2009, but dropped off abruptly, again, in 2010, to 0.57 .

Distribution of malaria cases in Puerto Gaitán in 2009 and 2010 - In Puerto Gaitán, 192 cases of malaria (144 P. vivax and 48 P. falciparum) occurred in 2009, with 226 (79 P. vivax and 147 P. falciparum) occurring in 2010. Males made up nearly $60 \%$ of all cases in both 2009 and 2010 (Table II). More than $50 \%$ of the malaria cases in these two years occurred in people aged 16-40 years (Table II). Additionally, in 2009 , nearly $70 \%$ of malaria cases occurred in the urban setting, whereas the cases were more evenly distributed between urban and non-urban settings in 2010 (Table II). Over $60 \%$ of $P$. vivax cases occurred in urban settings; in contrast $P$. falciparum cases occurred nearly equally in both settings (Table II).

The distribution of malaria cases attributed to $P$. vivax and $P$. falciparum in Puerto Gaitán differed significantly between 2009 and 2010 (Table III; $\chi^{2}$ p < 0.001). Malaria cases in 2009 were dominated by $P$. vivax (144 of 192 cases), while in 2010, P. falciparum was more prevalent (147 of 226 cases). No differences in malaria case distribution were observed between males and females in 2009 and 2010 for either Plasmodium species (Table III; $\chi^{2} \mathrm{p}>0.25$ and $\mathrm{p}>0.20$ for $P$. vivax and $P$. falciparum, respectively). Similarly, there were no differences observed in malaria case distribution among age groups in 2009 and 2010 for either Plasmodium species (Table III; $\chi^{2} \mathrm{p}>0.20$ and $\mathrm{p}>0.25$ for $P$. vivax and $P$. falciparum, respectively). However, statistically significant differences were observed between urban and non-urban settings in 2009 and 2010 for each Plasmodium species (Table III; $\chi^{2} \mathrm{p}<0.01$ and $\mathrm{p}<0.05$ for $P$. vivax and $P$. falciparum, respectively). In 2009, 70\% (100 of 144) of $P$. vivax cases occurred in an urban setting, but only $50 \%$ (40 of 79) of $P$. vivax cases occurred in the same setting in 2010 (Table III). The distribution of $P$. falciparum cases was reversed between 2009 and 2010, with 60\% (29 of 48) of cases occurring in an urban setting in 2009 and $57 \%$ (84 of 147) of cases occurring in a non-urban setting in 2010 (Table III).

The number of $P$. vivax and $P$. falciparum cases were plotted versus month for both 2009 and 2010 (Fig. 2). In $2009, P$. vivax cases greatly outnumbered $P$. falciparum cases, especially during the dry season (Fig. 2, unshaded months). However, in 2010, P. falciparum was the dominant Plasmodium species and occurred primarily in the rainy season (Fig. 2, shaded months), with peak activity at the end of the dry season (March) and the beginning of the rainy season (April).

Between 2005 and 2010 (Table I), malaria cases in Meta fluctuated $(989$ - 5,610) with a general downward trend over time. According to Chaparro et al. (2013), the municipality of Puerto Gaitán had a high API in 2010, though many of the other municipalities within the Department of Meta had lower APIs. According to previ-

\section{TABLE I}

Distribution of malaria cases by Plasmodium species and $P$. vivax/P. falciparum ratio in the Department of Meta and the Municipality of Puerto Gaitán, Colombia (2005-2010)

\begin{tabular}{|c|c|c|c|c|c|}
\hline \multirow[b]{2}{*}{ Location } & \multirow[b]{2}{*}{ Year } & \multicolumn{3}{|c|}{$\begin{array}{l}\text { Malaria cases }{ }^{a} \\
\text { (n) }\end{array}$} & \multirow{2}{*}{$\begin{array}{l}\mathrm{Pv} / \mathrm{Pf} \\
\text { ratio }\end{array}$} \\
\hline & & $\mathrm{Pv}$ & $\mathrm{Pf}$ & Total & \\
\hline \multirow[t]{7}{*}{ Department of Meta } & 2005 & 3,951 & 1,659 & 5,610 & 2.38 \\
\hline & 2006 & 2,465 & 1,008 & 3,473 & 2.45 \\
\hline & 2007 & 974 & 460 & 1,434 & 2.12 \\
\hline & 2008 & 1,638 & 535 & 2,173 & 3.06 \\
\hline & 2009 & 795 & 199 & 994 & 3.99 \\
\hline & 2010 & 693 & 296 & 989 & 2.34 \\
\hline & Mean & 1,753 & 693 & & 2.53 \\
\hline \multirow{7}{*}{$\begin{array}{l}\text { Municipality of } \\
\text { Puerto Gaitán }\end{array}$} & 2005 & 169 & 56 & 225 & 3.02 \\
\hline & 2006 & 94 & 106 & 200 & 0.89 \\
\hline & 2007 & 44 & 40 & 84 & 1.10 \\
\hline & 2008 & 96 & 42 & 138 & 2.29 \\
\hline & 2009 & 150 & 54 & 204 & 2.78 \\
\hline & 2010 & 89 & 157 & 246 & 0.57 \\
\hline & Mean & 107 & 76 & & 1.41 \\
\hline
\end{tabular}

$a$ : the small number of mixed infection slides was added to each of the Plasmodium species columns; Pf: Plasmodium falciparum; Pv: Plasmodium vivax. 
ous reports, the average $\mathrm{Pv} / \mathrm{Pf}$ ratio is approximately 3:1 (Sivigila 2011a,b). Over the six-year period, in the Department of Meta, the Pv/Pf ratio varied around this reported average, whereas in Puerto Gaitán, the Pv/Pf ratio was lower (Table I); in 2010, P. falciparum cases significantly outnumbered $P$. vivax cases by nearly twofold (Tables I, III). These malaria case numbers in Puerto Gaitán do not reflect the overall trend for Colombia of a significant increase in malaria cases from 2009 to 2010 $(p<0.001$; Chaparro et al. 2013) or the fact that 2010 was determined to be an epidemic year. Nevertheless, with such a substantial proportion of $P$. falciparum cases in 2006, 2007, and 2010 in Puerto Gaitán, this municipality is at greater risk of inhabitants acquiring $P$. falciparum than might be evident from the relatively small overall case numbers in Meta.

In Puerto Gaitán, males and people aged 16-40 had a higher percentage of cases compared with females and other age groups in both 2009 and 2010, similar to findings throughout Colombia (Chaparro et al. 2013). In this town, persons aged 16-40 are often the heads of households and thus any illness due to malaria could result in local economic destabilization. Despite the gender and age difference in cases, one mortality of a 30 year-old female was registered in 2009, and another of a 15 year old male in 2010, the first such deaths in Puerto Gaitán (SDS Meta 2011).

Furthermore, 3,071 adult female An. darlingi the primary malaria vector in Colombia, were collected and identified in Puerto Gaitán over several months in 2009. Of these, 751 ( 24\%) were collected inside houses (HL Brochero, unpublished observations). In addition, An. darlingi, was identified from streams, river margins and fish ponds within Puerto Gaitán (HL Brochero, unpublished observations). Such fish ponds are frequently located near dwellings and may contribute to an increase

\section{TABLE III}

Distribution of malaria cases in Puerto Gaitán, Meta, Colombia in 2009 and 2010 according to Plasmodium species and pertinent demographic variables

\begin{tabular}{|c|c|c|c|c|}
\hline \multirow{2}{*}{$\begin{array}{l}\text { Plasmodium } \\
\text { species }\end{array}$} & \multirow[b]{2}{*}{ Variable } & \multicolumn{2}{|c|}{ Year } & \multirow{2}{*}{$\begin{array}{l}\chi^{2} \\
\mathrm{p}\end{array}$} \\
\hline & & 2009 & 2010 & \\
\hline P. vivax & & 144 & 79 & $<0.001$ \\
\hline P. falciparum & & 48 & 147 & \\
\hline \multirow[t]{11}{*}{ P. vivax } & Sex & & & \\
\hline & Male & 85 & 50 & $>0.25$ \\
\hline & Female & 59 & 29 & \\
\hline & Age group (years) & & & \\
\hline & $0-10$ & 23 & 14 & $>0.20$ \\
\hline & $11-15$ & 10 & 12 & \\
\hline & $16-40$ & 90 & 41 & \\
\hline & $>40$ & 21 & 12 & \\
\hline & Geographic setting & & & \\
\hline & Urban & 100 & 40 & $<0.01$ \\
\hline & Non-urban & 44 & 39 & \\
\hline \multirow[t]{11}{*}{ P. falciparum } & Sex & & & \\
\hline & Male & 32 & 84 & $>0.20$ \\
\hline & Female & 16 & 63 & \\
\hline & Age group (years) & & & \\
\hline & $0-10$ & 15 & 28 & $>0.25$ \\
\hline & $11-15$ & 4 & 21 & \\
\hline & $16-40$ & 23 & 75 & \\
\hline & $>40$ & 6 & 23 & \\
\hline & Geographic setting & & & \\
\hline & Urban & 29 & 63 & $<0.05$ \\
\hline & Non-urban & 19 & 84 & \\
\hline
\end{tabular}

TABLE II

Distribution of malaria cases in Puerto Gaitán, Meta, Colombia by year and by Plasmodium species according to the patients' sex, age group and geographical setting

\begin{tabular}{|c|c|c|c|c|c|c|c|c|}
\hline \multirow[b]{3}{*}{ Variable } & \multicolumn{4}{|c|}{ Year } & \multicolumn{4}{|c|}{ Plasmodium species } \\
\hline & \multicolumn{2}{|c|}{2009} & \multicolumn{2}{|c|}{2010} & \multicolumn{2}{|c|}{ P. vivax } & \multicolumn{2}{|c|}{ P. falciparum } \\
\hline & $\mathrm{n}$ & $\%$ & $\mathrm{n}$ & $\%$ & $\mathrm{n}$ & $\%$ & $\mathrm{n}$ & $\%$ \\
\hline \multicolumn{9}{|l|}{ Sex } \\
\hline Male & 117 & 60.94 & 134 & 59.29 & 135 & 60.54 & 116 & 59.49 \\
\hline Female & 75 & 39.06 & 92 & 40.71 & 88 & 39.46 & 79 & 40.51 \\
\hline \multicolumn{9}{|l|}{ Age group } \\
\hline $0-10$ & 38 & 19.79 & 42 & 18.58 & 37 & 16.59 & 43 & 22.05 \\
\hline $11-15$ & 14 & 7.29 & 33 & 14.60 & 22 & 9.87 & 25 & 12.82 \\
\hline $16-40$ & 113 & 58.85 & 116 & 51.33 & 131 & 58.74 & 98 & 50.26 \\
\hline$>40$ & 27 & 14.06 & 35 & 15.49 & 33 & 14.80 & 29 & 14.87 \\
\hline \multicolumn{9}{|c|}{ Geographical setting } \\
\hline Urban & 129 & 67.19 & 103 & 45.58 & 140 & 62.78 & 92 & 47.18 \\
\hline Non-urban & 63 & 32.81 & 123 & 54.42 & 83 & 37.22 & 103 & 52.82 \\
\hline
\end{tabular}


A $_{35}$

B

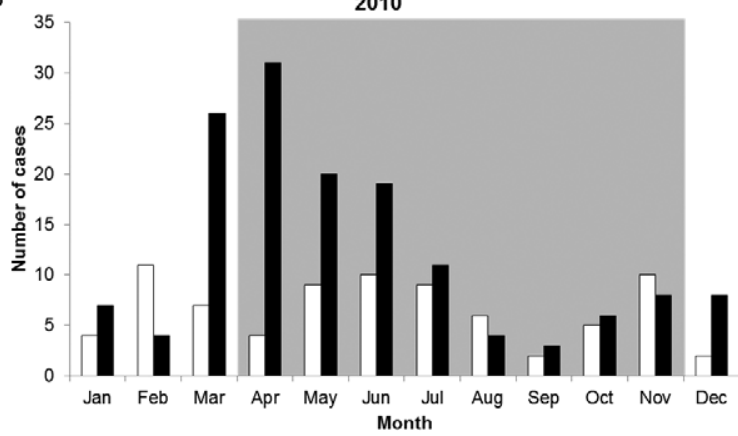

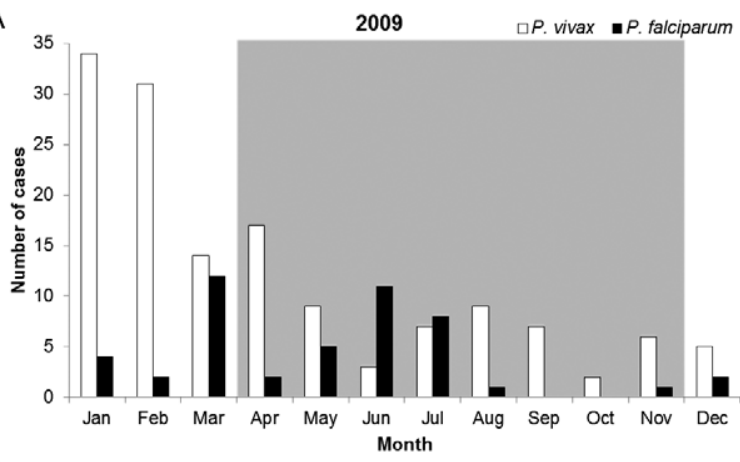

Fig. 2: distribution of malaria cases in Puerto Gaitán, Meta, Colombia, according to month. The months of the rainy season (April-November) are shaded.

in human-vector contact and possible malaria transmission (Brochero et al. 2006, Vittor et al. 2009). Puerto Gaitán is surrounded by several rivers, which provide additional breeding sites for An. darlingi throughout the year. Taken together, data in the present study provide evidence for urban transmission in Puerto Gaitán including both $P$. falciparum and $P$. vivax cases in children under the age of ten.

Only three localities in Colombia have previously reported urban malaria transmission: Quibdó (Chocó) and Buenaventura (Valle del Cauca) on the Colombian Pacific coast (Méndez \& Carrasquilla 1995, Olano et al, 1997, Ochoa \& Osorio 2006), and Puerto Carreño in eastern Colombia on the border with Venezuela (Jiménez et al. 2012).

\section{ACKNOWLEDGMENTS}

We are grateful to Nelson Peña, Armando Escobar, Secretaría Departamental de Salud del Meta, who collaborated with entomological studies.

\section{REFERENCES}

Arango E, Carmona-Fonseca J, Blair S 2008. In vitro susceptibility of Colombian Plasmodium falciparum isolates to different antimalarial drugs. Biomédica 28: 213-223.

Arevalo-Herrera M, Quiñones ML, Guerra C, Céspedes N, Giron S, Ahumada M, Piñeros JG, Padilla N, Terrientes Z, Rosas A, Padilla JC, Escalante AA, Beier JC, Herrera S 2012. Malaria in selected non-Amazonian countries of Latin America. Acta Trop 121: 303-314.

Bolaños O 2007. Programa de gobierno 2008-2011: capacidad para el desarrollo. Documento técnico. Puerto Gaitán, Julio 2007.
43P. Available from: http://www.puertogaitan-meta.gov.co/index.shtml

Brochero H, Quiñones ML 2008. Retos de la entomología médica para la vigilancia en salud pública en Colombia: reflexión para el caso malaria. Biomédica 28: 18-24.

Brochero H, Pareja P, Ortiz G, Olano V 2006. Breeding places and biting activity of Anopheles species in the municipality of Cimitarra, Santander, Colombia. Biomédica 26: 269-277.

Brochero H, Rey G, Buitrago L, Olano V 2005. Biting activity and breeding sites of Anopheles species in the municipality of Villavicencio, Meta, Colombia. J Am Mosq Control Assoc 21: 182-186.

Caicedo O, Ramirez O, Mourão MP, Ziadec J, Perez P, Santos JB, Quiñones F, Alecrim MG, Arévalo-Herrera M, Lacerda MV, Herrera S 2009. Comparative hematologic analysis of uncomplicated malaria in uniquely different regions of unstable transmission in Brazil and Colombia. Am J Trop Med Hyg 80: 146-151.

Camargo LM, Ferreira MU, Krieger H, de Camargo EP, de Silva LP 1994. Unstable hypoendemic malaria in Rondonia (western Amazon region, Brazil): epidemic outbreaks and work-associated indcidence in an agro-industrial rural settlement. Am J Trop Med Hyg 51: 16-25.

Chaparro P, Padilla J, Vallejo AF, Herrera S 2013. Characterization of a malaria outbreak in Colombia in 2010. Malar J 12: 330.

Enayati A, Hemingway J 2010. Malaria management: past, present, and future. Annu Rev Entomol 55: 569-591.

Faran ME 1980. Mosquito studies (Diptera: Culicidae) XXXIV. A revision of the Albimanus section of the subgenus Nyssorhynchus of Anopheles. Cont Am Entomol Inst 15: 1-215.

Gobernación del Meta 2004. El Meta: un territorio de oportunidades, IGAC, Available from: http://www.meta.gov.co/.

Hiwat H, Bretas G. 2011. Ecology of Anopheles darlingi Root with respect to vector importance: a review. Parasit Vectors 4: 177.

Jiménez P, Conn JE, Wirtz R, Brochero H 2012. Anopheles (Díptera: Culicidae) vectors of malaria in Puerto Carreño municipality, Vichada, Colombia. Biomédica 1: 13-21.

Méndez F, Carrasquilla G 1995. Epidemiología de la malaria en el área urbana de Buenaventura: análisis de la ocurrencia en el período 1987-1993. Colombia Médica 26: 77-84.

Méndez F, Carrasquilla G, Muñoz A 2000. Risk factors associated with malaria infection in an urban setting. Trans $R$ Soc Trop Med Hyg 94: 367-371.

Montoya-Lerma J, Solarte YA, Giraldo-Calderón GI, Quiñones ML, Ruiz-López F, Wilkerson RC, González R 2011. Malaria vector species in Colombia: a review. Mem Inst Oswaldo Cruz 106: 223-238.

Ochoa J, Osorio L 2006. Epidemiología de malaria urbana en Quibdó, Chocó. Biomédica 26: 278-285.

Olano V, Brochero H, Sáenz R, Quiñones M, Molina J 2001. Mapas preliminares de la distribución de Anopheles vectores de malaria en Colombia. Biomédica 21: 402-403.

Olano V, Carrasquilla G, Méndez F 1997. Transmisión de la malaria urbana en Buenaventura, Colombia: aspectos entomológicos. Rev Panam Salud Pública 1: 287-294.

Padilla J, Montoya R 2011. Guías de práctica clínica: Guía de atención clínica de malaria. Infection 15: 302-323.

Padilla J, Peña S 2002a. Situacion de la malaria en Colombia en 2002. Informe epidemiologico, Subdirección de Vigilancia/Instituto Nacional de Salud, Bogota. 
Padilla J, Peña S 2002b. Situación epidemiológica de la malaria en Colombia. Informe Quincenal Epidemiológico Nacional 7: 333-346.

Póvoa M, Conn J, Schlichting C, Amaral J, Segura M, da Silva A, dos Santos C, Lacerda RN, de Souza R, Galiza D, Santa Rosa E, Wirtz R 2003. Malaria vectors, epidemiology, and the reemergence of Anopheles darlingi in Belém, Pará, Brazil. J Med Entomol 40: 379-386.

Puerto Gaitán 2011. Puerto Gaitán en Meta, Colombia. Available from: http://www.puertogaitan-meta.gov.co/index.shtml

Rejmánková E, Rubio-Palis Y, Villegas L 1999. Larval habitats of anopheline mosquitoes in the Upper Orinoco, Venezuela. $J$ Vector Ecol 24: 130-137.

Rodríguez JCP, Uribe GA, Araújo RM, Narváez PC, Valencia SH 2011. Epidemiology and control of malaria in Colombia. Mem Inst Oswaldo Cruz 106: 114-122.

SDS Meta - Secretaría Departamental de Salud del Meta 2011. Laboratorio de Salud Pública y Oficina de Vigilancia Epidemiológica. Villavicencio, Meta, Colombia.
SEM - Servicio de Erradicación de la malaria 1957. Plan de erradicación de la malaria en Colombia. Vols. I, II, Ministerio de Salud Nacional, Bogotá.

Sivigila 2011a. Comportamiento de la malaria en Colombia según los casos notificados al Sivigila durante 2010- Corte 2 febrero 2011. Grupo ETV, Instituto Nacional de Salud, Bogotá, 5pp.

Sivigila 2011b. Sistema de vigilancia epidemiológica. Boletín vigilancia de la malaria en Colombia 52: 12.

Vittor A, Pan W, Gilman R, Tielsch J, Glass G, Shields T, SánchezLozano W, Pinedo V, Salas-Cobos E, Flores S, Patz J 2009. Linking deforestation to malaria in the Amazon: characterization of the breeding habitat of the principal malaria vector, Anopheles darling. Am J Trop Med Hyg 81: 5-12.

Vittor AY, Gilman RH, Tielsch J, Glass G, Shields T, Lozano WS, Pinendo-Cancino V, Patz JA 2006. The effect of deforestation on the human-biting rate of Anopheles darlingi, the primary vector of Falciparum malaria in the Peruvian Amazon. Am J Trop Med Hyg 74: 3-11. 